\title{
PELATIHAN PENGGUNAAN LABORATORIUM VIRTUAL SEBAGAI MEDIA PEMBELAJARAN KIMIA BAGI GURU DI MGMP KIMIA KABUPATEN BANYUWANGI
}

\author{
Oleh: \\ Rusly Hidayah ${ }^{1}$, Sukarmin ${ }^{2}$, Achmad Lutfi ${ }^{3}$ \\ ${ }^{1,23}$ Prodi Pendidikan Kimia FMIPA Unesa \\ rruslyhidayah@unesa.ac.id
}

\begin{abstract}
Abstrak
Pelatihan ini bertujuan untuk mengetahui kemampuan guru-guru di MGMP Kimia Kabupaten Banyuwangi dalam menggunakan media pembelajaran kimia berbasis komputer Chem Lab, mengintegrasikan media pembelajaran berbasis komputer Chem Lab dalam penyusunan Rencana Pelaksanaan Pembelajaran Kimia dan respon guru-guru di MGMP Kimia Kabupaten Banyuwangi terhadap pelatihan penggunan media pembelajaran berbasis komputer Chem Lab. Metode yang digunakan adalah pelatihan kepada guru-guru MGMP Kimia kabupaten Banyuwangi, Partisipan dari kegiatan ini adalah 18 guru MGMP Kimia Kabupaten Banyuwangi. Hasil dari pelatihan ini menunjukkan bahwa pelatihan telah berhasil dilaksanakan, ditunjukkan dengan $89 \%$ peserta telah memiliki kemampuan menggunakan program Chem Lab dengan kategori baik, $83,3 \%$ dengan kategori sangat baik dan $11.1 \%$ dengan kategori baik telah mampu menyusun Rencana Pelaksanaan Pembelajaran sesuai dengan kurikulum 2013 dan mengintegrasikan program Chem Lab sebagai media pembelajaran serta semua peserta pelatihan memberikan respon yang positif terhadap kegiatan pelatihan yang diberikan oleh Tim PKM.
\end{abstract}

Kata Kunci: Chem Lab, Integrasi, Media Pembelajaran, Respon Guru Kimia, RPP

Abstract

This training aims to know the ability of Banyuwangi MGMP Chemistry Teacher using instructional media chemistry computer-based Chem Lab, integrating media computer-based learning Chem Lab in preparation Chemistry Lesson Plan and response of Banyuwangi MGMP Chemistry Teacher to training, the use of computer-based learning media Chem Lab. The method is training to Banyuwangi MGMP Chemistry Teacher. Participants of this activity is 18 Banyuwangi MGMP Chemistry Teacher. The results of this training showed that the training has been successfully carried out, indicated by $89 \%$ of participants have had the ability to use the program Chem Lab with good category, $83.3 \%$ with very good category and $11.1 \%$ in both categories had been able to write lesson plans in accordance with curriculum 2013 and integrate Chem Lab program as a learning medium as well as all the trainees give a positive response to the training activities provided by PKM team.

Keywords: Chem Lab, Integration, Instructional media, Chemistry Teacher Respon, Lesson Plan

\section{PENDAHULUAN}

Kimia merupakan cabang dari IPA yang memiliki peran penting dalam perkembangan sains dan teknologi. Mengingat hal tersebut, peserta didik dituntut menguasai materi ajar kimia secara tuntas. Untuk memenuhi hal tersebut, guru harus kreatif dalam memilih media pembelajaran. Keberhasilan pembelajaran dipengaruhi oleh penggunaan media yang sesuai dengan tujuan tertentu (Arsyad: 2013).

Pelaksanaan kurikulum 2013 menuntut guru supaya berkreasi dalam proses belajar mengajar (PBM) agar pembelajaran berpusat pada siswa dengan memanfaatkan sarana dan prasarana yang ada, menerapkan model pembelajaran yang inovatif dengan harapan proses belajar mengajar menjadi bermakna bagi siswa (Permendikbud: 2016).

Pada bulan februari 2016 perwakilan MGMP Kimia Kabupaten Banyuwangi menyampaikan beberapa permasalahan kepada ketua jurusan kimia. MGMP Kimia Kabupaten Banyuwangi mengusulkan diadakan pelatihan penggunaan media dengan alasan materi kimia umumnya ditakuti siswa dan peralatan yang belum digunakan secara maksimal. Menurut Setiadi, R. dan Agus, A. (2000), suatu media pembelajaran 
yang berbasis multimedia komputer harus mencakup beberapa komponen seperti: suara, gambar, dan animasi. Media CHAM LAB mensimulaiskan kegiatan laboratorium untuk tingtkat SMA. Kondisi percobaan dibuat mirip seperti keadaan sesungguhnya. Sehingga, program in cocok untuk mempermudah memahami proses eksperimen (Zeynep Tatli and Alipasa Ayas: 2013). Oleh karena itu, untuk mengtatasi persoalan tersebut, pelathan penggunaan program CHEM LAB pada guru kimia seKabupaten Banyuwagi akan menjadi fokus pada penulisan artikel ini.

\section{METODE PELAKSANAAN}

Metode kegiatan ini berupa pelatihan kepada guru-guru MGMP Kimia kabupaten Banyuwangi. Kegiatan ini dilaksanakan melaui 3 tahap. Tahap pertama adalah persiapan. Pada tahap persiapan meliputi penyusunan instrumen kegiatan pengabdian kepada masyarakat dan berkoordinasi dengan MGMP Kimia Kabupaten Banyuwangi. Selanjutnya tahap kedua adalah pelaksanaan, yaitu tim pengabdian melaksanakan kegiatan pengabdian pada masyarakat. Terakhir, tahap evaluasi berupa umpan balik dari perwakilan guru dan pihak terkait. Evaluasi dari kegiatan pengabdian ini akan dilaksanakan melalui refleksi dan masukan dari peserta pada saat berakhirnya kegiatan. Pada tahap akhir, peserta diharapkan dapat melakukan kegiatan yaitu menyusun RPP dengan menggunakan Chem Lab sebagai media pembelajaran yang digunakan.

Komponen yang dinilai dalam pelatihan adalah Kemampuan menggunakan media Chem Lab, Rencana Pelaksanaan Pembelajaran (RPP) yang mengintegrasikan media Chem Lab, dan Angket Peserta. Partisipan dari kegiatan ini adalah 18 guru MGMP Kimia Kabupaten Banyuwangi.

\section{HASIL DAN PEMBAHASAN}

Kegiatan pelatihan ini dilaksakan melaui tiga tahap berdasarkan tahap-tahap pada kegiatan pengabdian, yaitu tahap persiapan, tahap pelaksanakan, dan tahap evaluasi.

\section{Tahap Persiapan}

Tahap kegiatan pengabdian masyarakat ini diawali dengan tim pengabdian menyusun instrumen kegiatan yang diperlukan, meliputi penyusunan materi kegiatan yang berupa power point tentang penjabaran RPP, dan penggunaan media pembelajaran Chem Lab, pembuatan angket respon guru sebagai peserta pelatihan, serta penyusunan instrumen penilaian kemampuan penggunaan media Chem Lab dan RPP yang mengitegrasikan media Chem Lab. Kedua, tim melakukan koordinasi dengan pihak terkait untuk pelaksanaan kegiatan, sehingga disepakati bahwa kegiatan pengabdian dilakukan pada hari Sabtu, tanggal 06 Agustus 2016 di SMAN 1 Banyuwangi dan akan dihadiri oleh guru-guru yang tergabung dalam MGMP Kimia kabupaten Banyuwangi.

\section{Tahap Pelaksanaan}

Tahap pelaksanaan yang bekerja sama dengan guru mata pelajaran kimia untuk melaksanakan pengabdian dan dihadiri oleh 18 orang guru. Pelaksanaan kegiatan PKM ini dilakukan oleh 3 (tiga) orang tim pengabdi dengan pokok bahasan yang disampaikan mengenai Pembuatan RPP dan Cara Menggunakan Media Pembelajaran Chem Lab

Berbagai pertanyaan diajukan secara antusias oleh para peserta dalam sesi tanya jawab. Secara garis besar, inti dari pertanyaan peserta adalah langkah-langkah pembuatan RPP, cara penggunaan Chem Lab, dan cara mengintegrasikan media Chem Lab dalam RPP

Berdasarkan penilaian Tim dari 18 peserta pelatihan, sebanyak 16 peserta (89\%) memiliki kemampuan mengoperasikan program Chem lab dengan kategori baik, sementara 2 peserta (11\%) memiliki kemampuan dengan kategori cukup baik. Kedua peserta tersebut kebetulan tidak membawa laptop pada saat pelatihan sehingga tidak dapat berlatih secara optimal karena terpaksa harus menunggu pinjaman dari temannya.

\section{Tahap Evaluasi}

Pada akhir kegiatan pelatihan, diberikan angket yang berisikan 8 (delapan) bbutir pertanyaan dan rekapitulasi hasilnya disajikan pada Tabel 1. Selanjutnya kepada peserta diberi tugas rumah berupa penyusunan RPP yang mengitegrasikan media Chem Lab. RPP tersebut dikirim melalui e-mail ke Tim PKM dan dilakukan penilaian. 
Tabel 1. Hasil Angket Respon Peserta Pelatihan

\begin{tabular}{|c|c|c|}
\hline \multirow[b]{2}{*}{ No. } & \multirow[b]{2}{*}{ Pertanyaan } & Jawaban \\
\hline & & $\begin{array}{c}\text { Tidak } \\
\text { menjawab }\end{array}$ \\
\hline 1. & $\begin{array}{l}\text { Apakah Anda senang pada kegiatan } \\
\text { pelatihan/workshop hari ini? }\end{array}$ & 18 \\
\hline 2. & $\begin{array}{l}\text { Apakah Anda merasa terganggu dengan kegiatan } \\
\text { seperti ini? }\end{array}$ & 18 \\
\hline 3. & $\begin{array}{l}\text { Apakah Anda bisa menerima materi dengan baik } \\
\text { yang disampaikan oleh dosen? }\end{array}$ & 18 \\
\hline 4. & Apakah kegiatan ini bermanfaat? & 18 \\
\hline 5. & $\begin{array}{l}\text { Apakah media pelatihan yang digunakan dapat } \\
\text { membantu Anda mengikuti pelatihan? }\end{array}$ & 17 \\
\hline 6 & $\begin{array}{l}\text { Apakah materi yang diberikan termasuk baru } \\
\text { menurut Anda? }\end{array}$ & 18 \\
\hline No. & Pertanyaan & Jawaban \\
\hline 7. & $\begin{array}{l}\text { Ungkapkan pendapat Anda yang lain tentang } \\
\text { pembelajaran/pelatihan hari ini! }\end{array}$ & $\begin{array}{l}\text { Kegiatan ini sangat bagus } \\
\text { serta bermanfaat, sangat } \\
\text { menarik tentang pembuatan } \\
\text { RPP berbasis kurikulum } 2013 \\
\text { dan menggunakan Chem Lab. }\end{array}$ \\
\hline 8. & $\begin{array}{l}\text { Apa yang ingin Anda peroleh bila dilakukan kegiatan } \\
\text { MGMP seperti ini lagi? }\end{array}$ & $\begin{array}{l}\text { Penyusunan LKS, dilakukan } \\
\text { lagi kegiatan semacam ini } \\
\text { secara rutin. }\end{array}$ \\
\hline
\end{tabular}

Berkaitan dengan kemampuan peserta dalam menyusun RPP yang mengintegrasikan program Chem lab dapat dinyatakan bahwa kemampuan membuat Rencana Pembelajaran (RPP) dari peserta pelatihan: (a) kategori baik apabila peserta pelatihan mampu membuat RPP sudah sesuai dengan silabus yang ada dengan urutan format RPP, jumlah peserta yang memperoleh kategori baik sekali ada 15 orang atau $83,3 \%$, (b) kategori baik apabila peserta pelatihan mampu membuat RPP sudah sesuai dengan silabus akan tetapi dalam membuat alat evaluasi tidak disertai dengan kunci jawaban, dalam kategori ini ada 2 orang peserta atau 11,1\% dan (c) kategori cukup dengan kriteria peserta pelatihan mampu membuat RPP dan alat evaluasi sesuai dengan format yang berlaku, tetapi kurang lengkap, yang masuk kategori ini ada 1 orang peserta atau 5,6\%. Dari data tersebut diatas, dapat diintepretasikan bahwa kemampuan peserta pelatihan dalam mengikuti pelatihan pembuatan RPP dengan mengintegrasikan program Chem Lab sebagai media pembelajaran menunjukan hasil secara rata-rata sangat baik.

\section{SIMPULAN DAN SARAN}

Hasil dari pelatihan ini menunjukkan bahwa pelatihan telah berhasil dilaksanakan, ditunjukkan dengan $89 \%$ peserta telah memiliki kemampuan menggunakan program Chem Lab dengan kategori baik, 83,3\% dengan kategori sangat baik dan $11.1 \%$ dengan kategori baik telah mampu menyusun Rencana Pelaksanaan Pembelajaran sesuai dengan kurikulum 2013 dan mengintegrasikan program Chem Lab sebagai media pembelajaran serta semua peserta pelatihan memberikan respon yang positif terhadap kegiatan pelatihan yang diberikan oleh Tim PKM.

Saran yang diusulkan adalah pelatihan akan lebih optimal jika dilaksanakan di salah satu sekolah di lingkungan MGMP Kimia Kabupaten Banyuwangi yang memiliki laboratorium komputer yang memadai sehingga bisa membantu guru-guru kimia di MGMP Kimia Kabupaten Banyuwangi yang belum memiliki laptop.

\section{DAFTAR PUSTAKA}

Arsyad, A. 2013. Media Pembelajaran. Jakarta : Rajawali Pers.

Permendikbud. 2016. Permendikbud No. 22 Tahun 2016. Tentang Standar Proses 
Rusly H., dkk., Pelatihan Penggunaan Laboratorium ...

Pendidikan Dasar dan Menengah. Jakarta: Kemendikbud.

Setiadi, R. dan Agus, A. 2000. Dasar-Dasar Pemrograman Software Pembelajaran. Bandung: FPMIPA Universitas Pendidikan Indonesia.
Zeynep Tatli and Alipasa Ayas. 2013. Effect of a Virtual Chemistry Laboratory on Student's Achievement. Journal Educational Technology \& Society, 16(1), 159-170. 